Western North American Naturalist 68(1), (C) 2008, pp. 119-122

\title{
SPOTTED BATS (EUDERMA MACULATUM) FROM MT. TAYLOR, NEW MEXICO
}

\author{
Keith Geluso $^{1}$
}

\begin{abstract}
The spotted bat (Euderma maculatum) is an elusive and rarely captured species in western North America. In the United States, it is known from 12 western states. In New Mexico, few individuals have been reported in recent years, and multiple individuals are known from 9 of 12 capture sites. This study reports on additional captures of $E$. maculatum from Mt. Taylor (Cibola County) for 2 consecutive summers and includes evidence of a reproducing population in the area. On 30 June/1 July 2006, I captured 4 individuals of E. maculatum, including a lactating female, and on 5 June 2007, I captured a nonreproductive female. The flight of this species was directional and deliberate; I captured 5 of 6 spotted bats that came low over the earthen pond. This study demonstrates how human-made sources of water in an arid region provide opportunities for many species of bats to drink.
\end{abstract}

Key words: Euderma maculatum, spotted bat, New Mexico, distribution, reproduction, audible calls.

The spotted bat (Euderma maculatum) is an elusive and rarely captured species in western North America, where it occurs from central Mexico to southwestern Canada (Black and Cosgriff 1999). In the United States, E. maculatum is known from 12 western states, including New Mexico (McMahon et al. 1979, Hall 1981, Finley and Creasy 1982, Gitzen et al. 2001). Unlike most other species of vespertilionids inhabiting New Mexico, spotted bats are known from relatively few localities in the state (12 localities, Perry et al. 1997). In recent years, few individuals have been reported in New Mexico, especially in areas where spotted bats once were regularly reported (Jones and Schmitt 1997). In fact, only 1 spotted bat was captured in the state between 1985 and 1995 (Perry et al. 1997). Because of its patchy distribution and limited abundance, only scant data on natural history are available in New Mexico. At present, E. maculatum is listed as threatened by the New Mexico Department of Game and Fish (Jones and Schmitt 1997).

In New Mexico, multiple individuals of $E$. maculatum have been reported at 9 of 12 capture sites. In addition, many of those sites have records of reproductively active females and include captures in different years (Findley and Jones 1965, Findley et al. 1975, Perry et al. 1997, Sherwin and Gannon 2005). At the remaining 3 sites, however, only a single record each is known-Aztec in San Juan County (Rodeck 1961), Mesilla Park in Doña Ana
County (Miller 1903), and Mt. Taylor in Valencia County (Reynolds 1981). It is unknown whether spotted bats regularly occur at these 3 sites or whether previous records represent transients or individuals from extirpated populations. This study reports on additional captures of E. maculatum from Mt. Taylor for 2 consecutive summers and includes evidence of a reproducing population in the area.

On 22 September 1978, a male E. maculatum was discovered impaled on a barbed wire fence near the summit of Mt. Taylor in Cibola County (formally part of Valencia County), New Mexico (Reynolds 1981). This location represents the highest elevational record for this species throughout its range (Reynolds 1981). Although the bat was discovered in September, it was mummified at the time of discovery. The mummified individual is a specimen at the Museum of Southwestern Biology (MSB), University of New Mexico, Albuquerque (MSB \#37688).

In 2006, I conducted a survey of bats on Mt. Taylor by placing mist nets (Avinet Inc., Dryden, NY) over water at 2 locations. This survey was part of a larger study examining $E$. maculatum at historical sites of occurrence in New Mexico. On 17 May, I set nets over a small, steel-rimmed stock tank (about $2 \mathrm{~m}$ in diameter) at American Canyon Spring $\left(35^{\circ}\right.$ $16.691^{\prime} \mathrm{N}, 107^{\circ} 33.647^{\prime} \mathrm{W}$, NAD 83, elevation $2885 \mathrm{~m}$ ). The tank was located in a rectangular-shaped meadow surrounded mainly by

${ }^{1}$ Department of Biology, University of Nebraska at Kearney, Kearney, NE 68849. E-mail: gelusok1@unk.edu 
TABLE 1. Spotted bats (Euderma maculatum) captured on Mt. Taylor, Cibola County, New Mexico, during the night of 30 June-1 July 2006 (1st four individuals) and on 5 June 2007 (last individual). Times of capture are Mountain Daylight Savings Time. Age is based on examination of epiphyses in bones of the wing (Anthony 1988). Forearm measurements were taken to the nearest $0.5 \mathrm{~mm}$.

\begin{tabular}{lccccc}
\hline Sex & Length of forearm $(\mathrm{mm})$ & Age & Body mass $(\mathrm{g})$ & Reproductive status & Time of capture \\
\hline Female & 54.0 & Adult & 16.9 & lactating & $22: 19$ \\
Female & 53.0 & Adult & 15.3 & nonreproductive & $22: 24$ \\
Male & 50.0 & Adult & 14.9 & - & $22: 40$ \\
Female & 54.5 & Adult & 17.8 & nonreproductive & $03: 27$ \\
Female & 52.0 & Adult & 15.2 & nonreproductive & $23: 10$ \\
\hline
\end{tabular}

Colorado blue spruce (Picea pungens), Douglas-fir (Pseudotsuga menziesii), and quaking aspen (Populus tremuloides). On this night, I captured 27 bats representing 5 species, including the silver-haired bat (Lasionycteris noctivagans, $10 \widehat{0} \widehat{0})$, long-legged myotis (Myotis volans, $60^{\circ}$ and 3 ㅇ $q$ ), long-eared myotis $(M$. evotis, $1 \delta^{\hat{\sigma}}, 2 \uparrow q$, and 1 unknown sex), fringed

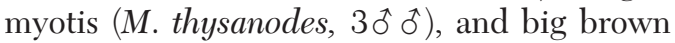
bat (Eptesicus fuscus, 1 1 ). That evening, I did not capture E. maculatum or hear its conspicuous audible calls. All bats were individually marked with a dot of permanent ink on their wing and released at the site of capture.

On 30 June, I set nets over a large earthen pond $(21 \times 31 \mathrm{~m}, 0.7 \mathrm{~m}$ deep; T12N, R8W, SW1/4 Sec. $22,35^{\circ} 14.902^{\prime} \mathrm{N}, 107^{\circ} 40.243^{\prime} \mathrm{W}$, NAD 83, elevation $2600 \mathrm{~m}$ ) in a shallow valley situated on a high plateau about $6 \mathrm{~km}$ west of the peak of Mt. Taylor. I placed three 18-m nets across the shallow pond and monitored nets from dusk to dawn. The pond was in a small opening $(50 \times 50 \mathrm{~m})$ surrounded by ponderosa pines (Pinus ponderosa) along with some scattered pinyon pines (Pinus edulis), junipers (Juniperus scopulorum and others), and Gambel oak (Quercus gambelii). North of the site, a woodland of pinyon pine and juniper was located on higher south-facing slopes. Small cliffs were located $<1 \mathrm{~km}$ from the pond, but many large cliffs were located $<12 \mathrm{~km}$ from the pond. On this night, I observed the 1st bats overhead at 20:55 (Mountain Daylight Savings Time) and captured the 1st bat ( $L$. noctivagans) at 20:56. I captured 195 bats representing at least 10 species, including $L$. noc-

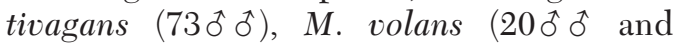
12 우), E. fuscus (220 0 ond 9 우 우), California myotis / western small-footed myotis (M. californicus/ciliolabrum, $160 \hat{0}$ and $8 \% q$ ), $M$.

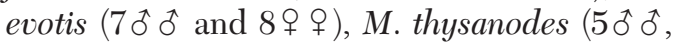
3 우, and 1 unknown sex), hoary bat (Lasiurus

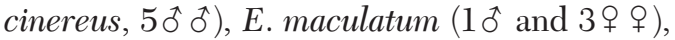

Yuma myotis (M. yumanensis, $10^{\widehat{)}}$, and Brazilian free-tailed bat (Tadarida brasiliensis, 10). In addition, I heard the conspicuous calls of the big free-tailed bat (Nyctinomops macrotis) overhead at 02:50 and 03:25 on 1 July.

Besides capturing 4 E. maculatum (Table 1), I also heard the conspicuous calls of others from 21:50 to 02:25. At 22:41, with 2 individuals already in small containers to obtain fecal pellets and another in hand, I heard another individual fly over my head. The volant $E$. maculatum seemed attracted to calls made by the individual in my hand. After I placed the captured bat in a container and it stopped vocalizing, the volant individual left the area.

On 5 June 2007, I returned to the same site where I captured spotted bats on 30 June and 1 July 2006. I again placed three 18-m nets across the shallow pond in about the same pattern but only monitored nets from dusk until 01:00 on 6 June. At 01:00, I removed mist nets from the pond. On this night, I observed the 1st bats overhead at 20:49 and captured the 1st bat (M. volans) at 20:56. On this night, I captured 80 bats representing at least 9 species, including $L$. noctivagans

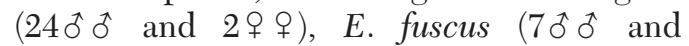
10 우 우), L. cinereus (11 ô ô and 1 ㅇ), M. volans

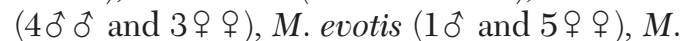
californicus/ciliolabrum (3ठ 0 and $2 q \%$ ), $M$. thysanodes $(3 \hat{\delta} \hat{\sigma}), T$. brasiliensis $(2 \hat{\delta} \hat{\sigma}$ and 1 i ), and E. maculatum (1오․, Table 1). In addition, I heard the conspicuous calls of $N$. macrotis overhead at 23:57. I only heard additional calls of E. maculatum at 21:45 and 00:31.

Audible calls of volant E. maculatum were loud, high-pitched clicks. Each click was short and sounded similar to 2 rocks or steel balls being hit together. When individuals were flying high overhead, clicks were spaced about 1 second apart. When individuals were directly over the pond and close to nets, the interval between clicks was distinctly shorter. For 
reference, audible calls of $N$. macrotis are even higher in pitch than those of E. maculatum, and each call of $N$. macrotis is drawn out compared to the short, sharp clicks of E. maculatum. Calls of N. macrotis are also spaced about 1 second apart.

Because I could easily locate spotted bats by their loud clicks, I observed that their flight was directional and deliberate. Of the 6 spotted bats that came low over the pond, I captured 5. Most individuals were captured near the center of the pond rather than at its edges. Each bat was captured shortly after it flew below the top edge of nets. The individual not captured circled over the pond but never flew below the top edge of nets.

In early evening on both nights, all individuals approached the pond from the west. Individuals not captured continued eastward towards higher elevations and the peak of Mt. Taylor. Three of 5 individuals captured produced $>5$ fecal pellets after being held in a small container for 60-67 minutes. This information suggests that roosting sites and some feeding sites likely were west of the pond at lower elevations. In 2006, spring and early summer were extremely dry in New Mexico, and many water sources on Mt. Taylor were dry (K. Geluso personal observation; J. Bates personal communication). In 2007, however, spring was wet in New Mexico, and all earthen ponds on Mt. Taylor had water (J. Bates personal communication). Rabe et al. (1998) demonstrated that E. maculatum can fly at least $38.5 \mathrm{~km}$ one-way between a roosting site and a drinking site. It is unknown whether spotted bats have always used this earthen pond to drink.

Human-made sources of water consisting of metal stock tanks and earthen ponds in arid regions provide opportunities for many species of bats to drink. These artificial water sources might be the most reliable sources of water for bats, especially in drought years (Tuttle et al. 2006). The earthen pond that I netted on Mt. Taylor was being filled by Forest Service personnel in mid-May 2006 and had a considerable quantity of water by late June. Land and resource managers who want to increase the activity of bats and other wildlife on land under their stewardship should consider maintaining artificial sources of water in areas otherwise devoid of surface water.

Surveys of bats were conducted on Mt. Taylor and surrounding areas prior to 1978 , but no record of E. maculatum was reported in the region (Findley et al. 1975). My capture of a lactating female and other individuals now provides evidence that a reproducing population exists on Mt. Taylor (Table 1). Hence, the previous record from 1978 likely was not a transient. Basic ecological information is lacking about E. maculatum in New Mexico and in other areas throughout its distribution. Additional studies determining distribution, local abundance, summer and winter roosts, foraging areas, diet, seasonal movements, and dates of reproductive activity would be beneficial for the conservation of this unusual and uncommon species.

I thank Mary Harner and Kenneth Geluso for assistance in the field, Jim Bates for assistance in locating open sources of water on Mt. Taylor, and Chuck Hagerdon for assistance in obtaining a special use permit from the National Forest Service. I thank Paul Cryan, William Gannon, Kenneth Geluso, and an anonymous reviewer for comments on earlier versions of this manuscript. I also thank Donna Howell, Mary Medina, James Stuart, and Chuck Hayes for their assistance and support with matters concerning my contract with the New Mexico Department of Game and Fish, Share with Wildlife Program. A single photographic voucher of E. maculatum from each year was deposited at MSB (MSB \# 125388 and 125389 , respectively).

\section{Literature Cited}

Anthony, E.L.P. 1988. Age determination in bats. Pages 47-58 in T.H. Kunz, editor, Ecological and behavioral methods for the study of bats. Smithsonian Institution Press, Washington, DC.

Black, H., and R. Cosgriff. 1999. Spotted bat / Euderma maculatum. Pages 118-119 in D.E. Wilson and S. Ruff, editors, The Smithsonian book of North American mammals. Smithsonian Institution Press, Washington, DC.

Findley, J.S., A.H. Harris, D.E. Wilson, and C. Jones. 1975. Mammals of New Mexico. University of New Mexico Press, Albuquerque.

FindLeY, J.S., AND C. JonEs. 1965. Comments on spotted bats. Journal of Mammalogy 46:679-680.

Finley, R.B., JR., and J. Creasy. 1982. First specimen of the spotted bat (Euderma maculatum) from Colorado. Great Basin Naturalist 42:360.

Gitzen, R.A., S.D. West, and J.A. Baumgardt. 2001. A record of the spotted bat (Euderma maculatum) from Crescent Bar, Washington. Northwestern Naturalist 82:28-30.

HaLL, E.R. 1981. The mammals of North America. 2nd edition. Volume 1. John Wiley \& Sons, Inc., New York. 
Jones, C., And C.G. Schmitt. 1997. Mammal species of concern in New Mexico. Pages 179-205 in T.L. Yates, W.L. Gannon, and D.E. Wilson, editors, Life among the muses: papers in honor of James S. Findley. Special Publications of the Museum of Southwestern Biology, Volume 3.

McMahon, E.E., C.C. OAKLeY, and S.P. Cross. 1979 First record of the spotted bat (Euderma maculatum) from Oregon. Great Basin Naturalist 41:270.

Miller, G.S., JR. 1903. A second specimen of Euderma maculatum. Proceedings of the Biological Society of Washington 16:165-166.

Perry, T.W., P.M. Cryan, S.R. Davenport, and M.A. Bogan. 1997. New locality for Euderma maculatum (Chiroptera: Vespertilionidae) in New Mexico. Southwestern Naturalist 42:99-101.

Rabe, M.J., M.S. Siders, C.R. Miller, and T.K. SNow. 1998. Long foraging distance for a spotted bat (Eu- derma maculatum) in northern Arizona. Southwestern Naturalist 43:266-269.

REYNOLDS, R.P. 1981. Elevational record for Euderma maculatum (Chiroptera: Vespertilionidae). Southwestern Naturalist 26:91-92.

Rodeck, H.G. 1961. Another spotted bat from New Mexico. Journal of Mammalogy 42:401.

Sherwin, R.E., AND W.L. GanNON. 2005. Documentation of an urban winter roost of the spotted bat (Euderma maculatum). Southwestern Naturalist 50:402-407.

Tuttle, S.R., C.L. Chambers, and T.C. Theimer. 2006. Potential effect of livestock water-trough modifications on bats in northern Arizona. Wildlife Society Bulletin 34:602-608.

Received 28 February 2007 Accepted 19 July 2007 